\title{
Could High Volume of Physical Activities in Early Pregnancy Interfere with Deep Placentation?
}

\author{
Chantale Vachon-Marceau, MD ${ }^{1}$ Mario Girard, $\mathrm{RT}^{2} \quad$ Michèle Bisson, MSc ${ }^{2,3}$ Suzanne Demers, MD, MSc ${ }^{1}$ \\ Isabelle Marc, MD, $\mathrm{PhD}^{2,4}$ Emmanuel Bujold, MD, $\mathrm{MSc}^{1,2}$
}

\footnotetext{
${ }^{1}$ Department of Obstetrics and Gynecology, Université Laval, Québec City, Quebec, Canada

${ }^{2}$ Centre de recherche du CHU de Québec, Mother, Child and Reproductive Health, Université Laval, Quebec City, Quebec, Canada

3 Department of Kinesiology, Université Laval, Québec City, Quebec, Canada

${ }^{4}$ Department of Pediatrics, Université Laval, Québec City, Quebec, Canada
}

Am J Perinatol Rep 2016;6:e421-e423.

\begin{abstract}
Address for correspondence Emmanuel Bujold, MD, MSc, FRCSC, Department of Obstetrics and Gynecology, Faculty of Medicine, Centre de recherche du CHU de Québec, Université Laval, 2705, Boulevard Laurier, Québec City, QC, Canada

(e-mail: emmanuel.bujold@crchudequebec.ulaval.ca).
\end{abstract}

\begin{abstract}
Keywords

- pregnancy

- physical activity

- placenta

- biomarker

- ultrasound

- preeclampsia

Background The impact of physical activity (PA) during pregnancy on obstetrical outcomes remains controversial. We followed pregnant women who reported more than 3 hours of sustained PA per week during the first trimester of pregnancy.

Cases Total five eligible women were followed. We observed small placenta from the first trimester (median: 0.68; interquartile [IQ]: 0.62-0.97 multiples of median [MoM]) to delivery (median: 0.82 ; IQ: $0.71-0.94 \mathrm{MoM}$ ), high uterine artery pulsatility index in the first (median: 1.82; IQ: 1.68-1.99 MoM) and second trimesters (median: 1.33; IQ: $1.11-1.56 \mathrm{MoM}$ ) of pregnancy. Placenta pathology revealed deep vasculopathy in three (60\%) cases. However, all participants delivered at term and none of them experienced preeclampsia.

Conclusion This small case series suggest that high PA volume in first trimester could interfere with deep placentation.
\end{abstract}

Physical activity (PA) has been recommended by the Society of Obstetricians and Gynecologists of Canada for uncomplicated pregnancies as a part of a healthy lifestyle. ${ }^{1}$ Moreover, the recent guidelines on hypertension supported the practice of exercise for maintenance of fitness in low-risk patients. ${ }^{2}$ It has been suggested that leisure time exercise could have a positive impact on placental growth, endothelial function, as well as oxidative stress reduction. ${ }^{3-5}$ A recent meta-analysis highlighted the potential benefit of PA on the prevention of preeclampsia, but the evidences regarding a dose-response relationship with exercise volume are limited. ${ }^{6}$ Furthermore, the impact of sustained exercise during the first trimester on placentation and placenta-related complications is still unclear. ${ }^{7-9}$ Although regular exercise in early pregnancy has been associated with an increased placental growth in mid- pregnancy, ${ }^{10}$ some evidences suggest a potential increase of severe preeclampsia in women of high volume of PA during first trimester. ${ }^{8}$ Recently, Ferland et al observed a significant decrease of placental growth factor concentration and a trend toward lower pregnancy-associated plasma protein A and placental volumes in women with higher PA frequency, suggesting a negative impact of sustained exercise on placental growth and function. ${ }^{7}$

With potential preventive measures such as aspirin and low-molecular-weight heparin for placenta-mediated complications, ${ }^{11-16}$ there is a growing interest for the study of early placentation. Several tools, including three-dimensional ultrasound $^{17,18}$ and biochemical markers have been used to identify women at risk of abnormal placentation and preeclampsia. We aimed to use such tools to evaluate placental received

September 15, 2016 accepted after revision October 20, 2016
DOI http://dx.doi.org/ $10.1055 / \mathrm{s}-0036-1597264$. ISSN 2157-6998.
Copyright $\odot 2016$ by Thieme Medical Publishers, Inc., 333 Seventh Avenue, New York, NY 10001, USA. Tel: +1(212) 584-4662.
License terms

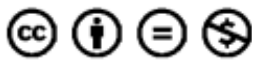


e422 Could High Volume of PAs in Early Pregnancy Interfere with Deep Placentation? Vachon-Marceau et al.

Table 1 Characteristics of five participants who reported high volume of physical activity during first trimester of pregnancy

\begin{tabular}{|c|c|c|c|}
\hline Characteristics & Median & Interquartile & Range \\
\hline Maternal age $(\mathrm{y})$ & 33 & $31-36$ & $29-38$ \\
\hline Body mass index $\left(\mathrm{kg} / \mathrm{m}^{2}\right)$ & 21 & $21-25$ & $21-26$ \\
\hline Mean arterial blood pressure $(\mathrm{mm} \mathrm{Hg})$ & 76 & $69-81$ & $64-82$ \\
\hline Gestational age at recruitment (wk) & 12.6 & $12.4-13.3$ & $12.4-13.4$ \\
\hline PAPP-A (MoM) ${ }^{17}$ & 0.54 & $0.33-0.72$ & $0.28-0.87$ \\
\hline First-trimester placental volume (MoM) & 0.68 & $0.62-0.97$ & $0.62-1.17$ \\
\hline First-trimester placental VFI (MoM) & 0.27 & $0.08-1.11$ & $0.07-1.83$ \\
\hline First-trimester UtA PI ${ }^{20}(\mathrm{MoM})$ & 1.82 & $1.68-1.99$ & $1.65-2.10$ \\
\hline Second-trimester UtA PI (MoM, $N=4$ ) & 1.33 & $1.11-1.56$ & $1.08-1.60$ \\
\hline Third-trimester UtA PI (MoM, $N=3)$ & 1.23 & - & $1.19-1.38$ \\
\hline Gestational age at birth (wk) & 40.0 & $39.0-40.6$ & $38.3-40.9$ \\
\hline Birth weight $(\mathrm{g})$ & 3,220 & $2,782-3,277$ & $2,608-3,300$ \\
\hline Birth weight (MoM) & 0.93 & $0.82-0.94$ & $0.71-0.95$ \\
\hline Placenta weight (g) & 424 & $370-489$ & $322-550$ \\
\hline Placenta weight (MoM) & 0.82 & $0.71-0.94$ & $0.61-1.05$ \\
\hline
\end{tabular}

Abbreviations: MoM, multiple of median adjusted for gestational age; PAPP-A, pregnancy-associated plasma protein A; UtA PI, uterine artery pulsatility index, VFI, vascularization flow index.

development during pregnancy in women who reported high PA volume during the first trimester of pregnancy.

\section{Cases}

Five women out of approximately 240 women who participated in a prospective cohort for the study of early biomarkers of preeclampsia reported more than three episodes of more than 1 hour of sustained (e.g., running, cross-country skiing, cross-fit training) PA every week over the first trimester. This volume of PA was selected because it represents twice the minimum recommended levels for Canadian adults. The exact PA volume could not be exactly reported retrospectively but all five participants reported between three and seven episodes of more than 1 hour of sustained PA every week. ${ }^{19}$ In comparison, we observed that only $8 \%$ of the participants in the entire cohort reported more than three episodes of PA per week, regardless of the intensity. All women signed an informed consent and the ethics committee of the CHU de Québec approved the study. - Table 1 reports the characteristics (median, interquartile, and ranges) of the five participants. We observed that most participants showed indices suggesting impaired deep placentation with high resistance of uterine artery pulsatility index, small placenta volume, low placenta vascularization, as well as small birth and placenta weight (-Table 1). Of note, none of the participants had preeclampsia, two of them had a small for gestational age neonate, one had a placental abruption, and placenta pathology revealed signs of deep vasculopathy in three of them. All of them delivered at term.

\section{Conclusion}

We observed signs of impaired placentation in three to five (60-100\%) out of five participants who reported high volume of PA during the first trimester of pregnancy. Our observation suggests that high volume of PA could delay or interfere with physiological placentation and could explain studies that reported a greater risk of severe preeclampsia in women with high volume of PA during pregnancy. ${ }^{8}$

Our conclusions are severely limited by the study design (case series) and the small sample size leading to significant risk of bias. Based on our results, we cannot recommend any maximal level of PA volume and we cannot suggest that high PA volume is a significant risk factor for deep placentation disorder or adverse perinatal outcomes. However, the observation is sufficiently important to warrant a large prospective study that could lead to important change in clinical recommendations regarding optimal PA during pregnancy.

\section{Funding}

S.D., I.M., and E.B. are supported by the Fonds de la recherche du Québec - Santé (FRQ-S). M.B. is a doctoral scholarship holder from the Canadian Institutes of Health Research. The study was funded by the Jeanne et JeanLouis Lévesque Perinatal Research Chair at Université Laval.

Conflict of Interest

All authors disclosed no conflict of interest of financial or other nature. 


\section{References}

1 Davies GA, Wolfe LA, Mottola MF, MacKinnon C; Society of Obstetricians and Gynecologists of Canada, SOGC Clinical Practice Obstetrics Committee. Joint SOGC/CSEP clinical practice guideline: exercise in pregnancy and the postpartum period. Can J Appl Physiol 2003;28(3):330-341

2 Magee LA, Pels A, Helewa M, Rey E, von Dadelszen P; Canadian Hypertensive Disorders of Pregnancy Working Group. Diagnosis, evaluation, and management of the hypertensive disorders of pregnancy: executive summary J Obstet Gynaecol Can 2014; 36(5):416-41

3 Weissgerber TL, Wolfe LA, Davies GA. The role of regular physical activity in preeclampsia prevention. Med Sci Sports Exerc 2004; 36(12):2024-2031

4 Jackson MR, Gott P, Lye SJ, Ritchie JW, Clapp JF III. The effects of maternal aerobic exercise on human placental development: placental volumetric composition and surface areas. Placenta 1995;16(2):179-191

5 Clapp JF. Influence of endurance exercise and diet on human placental development and fetal growth. Placenta 2006;27(6-7): 527-534

6 Aune D, Saugstad OD, Henriksen T, Tonstad S. Physical activity and the risk of preeclampsia: a systematic review and meta-analysis. Epidemiology 2014;25(3):331-343

7 Ferland S, Bujold E, Giguère Y, Girard M, Demers S, Forest JC. Association between physical activity in early pregnancy and markers of placental growth and function. J Obstet Gynaecol Can 2013;35(9):787-792

8 Østerdal ML, Strøm M, Klemmensen AK, et al. Does leisure time physical activity in early pregnancy protect against pre-eclampsia? Prospective cohort in Danish women. BJOG 2009;116(1): 98-107

9 Szymanski LM, Satin AJ. Strenuous exercise during pregnancy: is there a limit? Am J Obstet Gynecol 2012;207(3):179.e1-179.e6

10 Clapp JF III, Rizk KH. Effect of recreational exercise on midtrimester placental growth. Am J Obstet Gynecol 1992;167(6):1518-1521
11 Roberge S, Demers S, Nicolaides KH, Bureau M, Côté S, Bujold E. Prevention of pre-eclampsia by low-molecular-weight heparin in addition to aspirin: a meta-analysis. Ultrasound Obstet Gynecol 2016;47(5):548-553

12 Bujold E, Roberge S, Lacasse Y, et al. Prevention of preeclampsia and intrauterine growth restriction with aspirin started in early pregnancy: a meta-analysis. Obstet Gynecol 2010;116(2 Pt 1): 402-414

13 Roberge S, Sibai B, McCaw-Binns A, Bujold E. Low-dose aspirin in early gestation for prevention of preeclampsia and small-forgestational-age neonates: meta-analysis of large randomized trials. Am J Perinatol 2016;33(8):781-785

14 Bergeron TS, Roberge S, Carpentier C, Sibai B, McCaw-Binns A, Bujold E. Prevention of preeclampsia with aspirin in multiple gestations: a systematic review and meta-analysis. Am J Perinatol 2016;33(6):605-610

15 Roberge S, Giguère Y, Villa P, et al. Early administration of low-dose aspirin for the prevention of severe and mild preeclampsia: a systematic review and meta-analysis. Am J Perinatol 2012;29(7): 551-556

16 Roberge S, Giguère Y, Villa P, et al. Early administration of low-dose aspirin for the prevention of severe and mild preeclampsia: a systematic review and meta-analysis. Am J Perinatol 2014;31(6):e3

17 Demers S, Girard M, Roberge S, et al. First-trimester placental and myometrial blood perfusion measured by three-dimensional power Doppler in preeclampsia. Am J Perinatol 2015;32(10): 920-926

18 Effendi M, Demers S, Giguère Y, et al. Association between firsttrimester placental volume and birth weight. Placenta 2014;35(2): 99-102

19 Tremblay MS, Warburton DE, Janssen I, et al. New Canadian physical activity guidelines. Appl Physiol Nutr Metab 2011; 36(1):36-46, 47-58

20 Gómez O, Figueras F, Fernández S, et al. Reference ranges for uterine artery mean pulsatility index at $11-41$ weeks of gestation. Ultrasound Obstet Gynecol 2008;32(2):128-132 